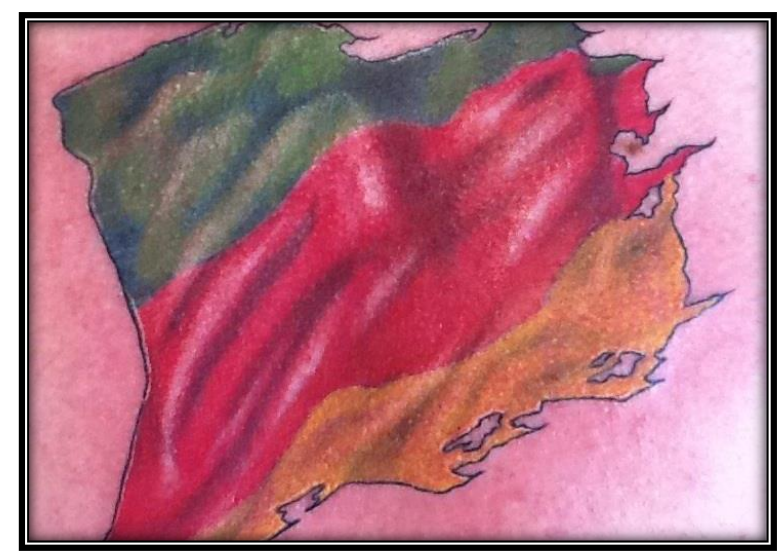

\title{
O discurso ufanista materializado no corpo
}

The vainglorious discourse incorporated on the body

Naiara Souza da Silva ${ }^{1}$

Stella Aparecida Leite Lima ${ }^{2}$

\begin{abstract}
Resumo:
Este texto visa a refletir, no âmbito da Análise de Discurso (AD) de tradição pecheuxtiana, sobre o imaginário que perpassa a representação de um sujeito gaúcho acerca do Estado do Rio Grande do Sul (RS). Este sujeito, afetado por um imaginário social sobre os valores de seu Estado, materializa um discurso ufanista em seu corpo, por meio da tatuagem da bandeira do RS. Entendendo as tatuagens como textos portadores de discursividade, nosso objetivo é produzir uma leitura a partir de sentidos que ela nos possibilita, levando em consideração a questão da constituição de sentido e a noção de memória discursiva. Com relação ao sujeito tatuado, em seu gesto simbólico de tatuar a bandeira, observamos a presença do político, em especial quando produz um discurso de grandeza de seu Estado.
\end{abstract}

Palavras-chave: Imaginário. Gaúcho. Tatuagem. Sentido.

\section{Abstract:}

This paper aims to reflect, in the context of Michel Pêcheux's Discourse Analysis (DA), on the imaginary that passes through the representation of a gaucho subject about the State of Rio Grande do Sul (RS). This subject, affected by a social imaginary about the values of its State, embodies a vainglorious speech on its body through the tattoo of the flag of RS. Understanding tattoos as discursive texts, our goal is to produce a reading from the senses that it enables us, taking into account the constitution of meaning and the notion of discursive memory. Regarding the tattooed subject, in its symbolic gesture of tattooing the flag, we observe the presence of the politician, especially when it produces a speech of greatness of its State.

Keywords: Imaginary; Gaucho; Tattoo; Sense.

\footnotetext{
${ }^{1}$ Universidade Católica de Pelotas (UCPEL). Mestre em Letras (UPCEL). Doutoranda no Programa de PósGraduação em Letras: Linguística Aplicada (PPGL/UCPEL), atuando na linha de pesquisa: Texto, Discurso e Relações Sociais. E-mail: naiaraa_souza@hotmail.com. Membro do Laboratório de Estudos em Análise de Discurso (LEAD/UCPEL). End. Rua Félix da Cunha, 412, sala 415C, Centro, 96010000 - Pelotas, RS

${ }^{2}$ Universidade Católica de Pelotas (UCPEL). Licenciada em Letras (UCPEL). Especialista em Letras pelo Curso de Especialização lato sensu da Universidade Federal de Pelotas (UFPEL). Mestranda no Programa de PósGraduação em Letras: Linguística Aplicada (PPGL/UCPEL), atuando na linha de pesquisa: Texto, Discurso e Relações Sociais. E-mail: staple_li@ hotmail.com.
} 


\section{Considerações introdutórias}

Este texto ${ }^{3}$ visa a refletir, no âmbito da Análise de Discurso (AD) de tradição pecheuxtiana, sobre o imaginário que perpassa a representação de um sujeito gaúcho acerca do Estado do Rio Grande do Sul (RS). Este sujeito, afetado por um imaginário social acerca dos valores de seu Estado, textualiza em seu corpo uma tatuagem. No nosso entender, a mesma deve ser considerada como um texto portador de discursividade. Sendo assim, compreendemos que na textualização de uma tattoo materializam-se discursos e é esse processo de significação, de construção/formulação de sentidos que nos interessa. Tratando-se do presente trabalho, nosso objeto de investigação refere-se à tatuagem da bandeira do RS, materializada no corpo do sujeito num contexto sócio-histórico específico, a Semana Farroupilha.

A leitura que fazemos diz respeito aos efeitos de sentido que ressoam na tatuagem em questão - emergem sentidos relacionados ao imaginário de um Estado singular, construído ao longo do tempo, presentes na referida tatuagem. Conforme Silva (2014), trabalhar com a interpretação de uma tatuagem não se trata de desvendar um sentido único, ao contrário, trata-se de observar os modos como, ao marcar a própria pele, o sujeito produz sentidos por meio da textualização da tattoo.

No entendimento de Pires (2001), a tatuagem funciona como um registro, e esse funcionamento ultrapassa a questão estética. Utilizando-nos de suas palavras, "o indivíduo que a adquire, transfere para ela a memória de um fato ou de uma situação. A lembrança, que antes habitava na memória, ou em determinados objetos externos ao corpo, agora é incrustada à pele" (PIRES, 2001. p. 98). Essas lembranças, a nosso ver, constituem os sentidos e eles, por sua vez, são perpassados pela historicidade ${ }^{4}$ que cada desenho (tattoo) carrega num determinado momento sócio-histórico. Portanto, consideramos que a construção do sentido de uma tatuagem não é sistêmica e sim, subjetiva $^{5}$, e o gesto de se tatuar, é um gesto de interpretação, pois o sujeito sempre está instado a interpretar.

\footnotetext{
${ }^{3}$ Uma versão deste trabalho foi apresentada no XII Círculo de Estudos Linguísticos do Sul - CELSUL, no mês de setembro de 2016, na Universidade Federal de Santa Maria (UFSM).

${ }^{4} \mathrm{Na} \mathrm{AD}$, interessa-nos trabalhar com a noção de historicidade e não, com a noção de história do ponto de vista cronológico. Isto porque importa observar o modo como a história se inscreve nos processos discursivos e, não sua linearidade. Nessa perspectiva, a historicidade reafirma a relação constitutiva entre linguagem e exterioridade.

${ }^{5}$ A noção de subjetividade é aqui tratada por nós, enquanto efeito de evidência, pois desde sempre o indivíduo é interpelado em sujeito pela ideologia. Em outras palavras, o sujeito acredita que assume posições pessoais, quando, de fato, assume posições afetadas ideologicamente. São as evidências dos sentidos que dão ao sujeito a realidade, funcionando pelos esquecimentos da ordem ideológica e da ordem da formulação, em que o assujeitamento se realiza sob a forma da autonomia.
} 
Ferreira (2012) acredita que na sociedade contemporânea, a tatuagem exerce papel na construção do sujeito, constituindo signos identitários, cuja finalidade expressa socialmente singularidade, partindo de uma ilusória escolha pessoal. Ainda na concepção da autora, a tattoo reflete características biográficas do sujeito que pratica o gesto. Por um mesmo viés, Orlandi (2004) escreve que a prática da tatuagem faz parte de um "ritual" de "inscrever letra na pele", nele está "a escolha do motivo até o lugar em que é feita. Isso passa, segundo um tatuador, por um gesto primitivo, de uma relação originária consigo mesmo e com o mundo; [...] é uma forma de dar mais poder ao corpo" (p. 119). De acordo com a autora recém-citada, muitos são os fatores motivacionais para o sujeito "depositar" um desenho na sua pele e, este é um movimento interessante e sintomático, pois mostra que o corpo passa a ser entendido como um texto.

Em outro trabalho, a mesma autora (2012a) retoma a tatuagem como um processo de individua(liza)ção do sujeito que se tatua. Esse processo de individua(liza)ção decorre, no seu entendimento, da necessidade do sujeito de individualizar seu corpo no/do corpo social, por meio do gesto simbólico-histórico de inscrever a letra na pele.

Nesse caminho, se bem entendemos as três autoras referidas neste texto, Pires (2001), Ferreira (2012) e Orlandi (2004; 2012a), é pertinente escrevermos que a tatuagem estabelece um campo de significação que compreende o próprio corpo do sujeito como um espaço, uma região de sentidos escritos na pele, produzindo efeitos de sentidos próprios a determinadas condições políticas e ideológicas. Assim, ao tratar da tatuagem, no presente trabalho, compreendemos que existe um imaginário sobre o gaúcho que rege o funcionamento do gesto do sujeito de se tatuar, e este gesto, produz efeitos de sentidos interferindo tanto na sua identidade quanto nos processos de individua(liza)ção.

Recorrendo a Orlandi (2012a), podemos complementar escrevendo que é através do corpo que cada sujeito pode "desempenhar seu desejo de reconhecimento como reconhecimento de seu desejo e de seu ser" (p. 193). De acordo com o seu entendimento, os dizeres transbordam dos outdoors, como um excesso de linguagem o tempo todo visível ao sujeito, para o próprio corpo resultando num excesso de marcas visíveis e necessárias para a afirmação de si.

No ponto de vista de Ernst-Pereira (2004), o desejo do sujeito é 
"o desejo do corpo e do outro, corpo exposto ao olhar desse outro e, por isso, (com)figurado e (re)configurado incessantemente, pois é a partir desse olhar que a identidade e a subjetividade se estabelecem. Na realidade, o "eu" é uma produção imaginária que se cristaliza a partir da imagem que o sujeito tem de seu próprio corpo e de auto-imagens refletidas para ele por outros, e isso se dá através do simbólico (p. 2).

Nessa perspectiva do corpo como objeto submetido à linguagem, é que pensamos sua constituição e seu funcionamento (cf. LEANDRO-FERREIRA, 2013. p. 99), pois nessa linha teórica, o corpo não é conceituado como uma dádiva da natureza, e sim o resultado de uma construção, sendo ele interpelado assim como o sujeito. Orlandi (2012b), quando trabalha a questão do corpo, diz que "enquanto corpo empírico, ele é apenas carne. Todavia, quando o corpo é produzido em um processo de significação, onde trabalha a ideologia, ele é corpo simbólico, chamado de corpodiscurso" (p. 85).

Consideramos então, diante a reflexão aqui realizada, o corpodiscurso do sujeito tatuado, sua materialidade significativa e os efeitos de sentido produzidos enquanto corpo de um sujeito assujeitado à ideologia e ao inconsciente, e também, determinado historicamente. É inscrito numa Formação Discursiva (FD) ${ }^{6}$, que o sujeito singulariza seu corpo, individualiza-se pelo gesto de se tatuar, materializando os saberes dessa FD em seu próprio corpo. Dito de outra maneira, é na FD que o sujeito constrói sua identidade e que o sentido adquire um efeito de evidência.

Relacionando o dito acima ao sujeito tatuado com a bandeira do RS, compreendemos que se trata de um sujeito inscrito numa FD, interpelado pelos saberes oriundos dessa FD, cujos sentidos que emergem do interdiscurso relacionam-se à valorização e à idolatria ao Estado, ou seja, nessa FD perpassa uma Formação Ideológica (FI) com pressupostos entendidos por nós, como ufanistas. Nesse contexto, o sujeito tatuado textualiza tais saberes em seu próprio corpo, resultando na tatuagem da bandeira do RS.

Esta tatuagem nos causou estranhamento, por se referir a um desenho de uma bandeira da época da Revolução Farroupilha, materializada na contemporaneidade, no período da Semana Farroupilha. Nesse ínterim, nos questionamos: que bandeira é esta,

\footnotetext{
${ }^{6}$ Formação Discursiva (FD) é um dos princípios teóricos-metodológicos da AD. Sua configuração é de responsabilidade do analista, que precisa considerar a historicidade do discurso que está sendo analisado; portanto, não é o gênero discursivo que define essa questão. Esta noção, a nosso entender, identifica um domínio de saber e dissimula, pela transparência de sentido que nela se constitui, sua dependência com respeito ao interdiscurso, intrincado no complexo das formações ideológicas (cf. CAZARIN, 2005).
} 
que imaginário perpassa a representação dessa bandeira e da representação do gaúcho, e que efeitos de sentidos podem emergir na leitura desta tattoo?

Para um possível efeito de resposta aos questionamentos acima, recorremos ao estudo de Petri (2004) na busca da compreensão da questão do imaginário sobre o gaúcho e, o que este imaginário social influencia no funcionamento do imaginário do sujeito quando do gesto de se tatuar e, nas possíveis interpretações da sociedade leitora quando da leitura/visualização da tattoo do sujeito.

\section{A construção do imaginário do gaúcho}

Primeiramente, acreditamos necessário explicarmos o que estamos entendendo por imaginário. $\mathrm{Na} \mathrm{AD}$, entendemos que o funcionamento dos processos discursivos ancora-se nas formações imaginárias, conforme as orientações de Pêcheux $(1990 / 2010)^{7}$. Ou seja, “os mecanismos de funcionamento do discurso repousam no que chamamos de formações imaginárias. Assim não são os sujeitos físicos nem os seus lugares empíricos como tal, isto é, como estão inscritos na sociedade, [...] mas suas imagens que resultam de projeções" (ORLANDI, 2012c, p. 40). Portanto, esse mecanismo imaginário produz imagens dos sujeitos e também, do objeto do discurso, num contexto específico.

Nessa perspectiva, recorremos, ainda que breve, às considerações de Petri (2004) sobre a representação do gaúcho. Esta representação, segundo o seu estudo, é da ordem do imaginário social (construído e instituído), pois, “existem formações imaginárias que regem as relações do gaúcho consigo mesmo, com o mundo e com o outro" (p. 125). Nesse sentido, as acepções da designação "gaúcho" variam ao longo dos tempos, conforme recuperação/reinvenção imaginária, produzindo efeitos de sentido constitutivos de sua identidade.

De acordo com a autora mencionada, há várias hipóteses da origem da designação "gaúcho" que variam desde sua origem etimológica até efeitos de sentido mais específicos, todos relacionados entre o homem e às coisas da terra. Essa relação entre o homem e a terra, construída em tempos da civilização, sofreu alteração e foi responsável pelas lutas sociais, resultando nas formas de designações.

\footnotetext{
7 A formatação desta bibliografia está disposta na seguinte ordem: 1990 refere-se a 1. edição da obra/2010 refere-se a edição que estamos utilizando no estudo. A partir deste momento, poderão ser encontradas no presente texto referências dispostas nesse modelo.
} 
Encaminhando a um percurso histórico, no século XVII, a entrada dos colonizadores espanhóis na região das missões, no pampa rio-grandense, introduziu novos hábitos, dentre eles o da pecuária. Os índios foram "ensinados" a trabalhar com o gado de forma civilizada, e logo, se adaptaram à montaria e à lida da pecuária, desenvolvendo armas como a lança e a boleadeira. Concomitantemente a esse processo de migração, os índios foram explorados tanto pelos conquistadores bandeirantes quanto pelos catequizadores jesuítas. O rompimento, posterior, dessa "aliança trabalhista" entre bandeirantes e índios, ocasionou a morte e/ou fuga de muitos indígenas.

Conforme relato de Petri (2004), esse massacre indígena se explica porque o "homem civilizado" chega ao Brasil com o propósito de fazer história, e o nativo é visto como um ser que não tem história própria. Nesse entendimento, utilizando-nos das palavras da autora, "o nativo é tomado como integrante de um grupo social não desenvolvido, selvagem. [...] o branco sente-se a vontade para impor-se e dominar social e culturalmente, contando a história sobre o nativo e não do nativo" [grifos da autora] (p. 128). Por isso, precisamos colocar em evidência os fatos dispostos sobre essa história que representam o olhar do "outro" sobre o nativo e sobre o gaúcho, esse outro que representa o estrangeiro, que detém o poder da palavra e, através dela atribui sentidos sobre os mesmos, construindo todo um imaginário pejorativo.

Se bem entendemos a continuação do relato da autora, com a ausência desse trabalho indígena, o gado ficou solto pelo território rio-grandense. Isto ocasionou um imaginário sobre o Estado, denominando-o "terra de ninguém", despertando a curiosidade de outros habitantes de várias regiões. Dentre eles, encontravam-se os "gaúchos", aqueles advindos da região do pampa uruguaio e argentino, cuja denominação sinalizava o sentido de "bandidos" e "malfeitores" - tais sentidos foram cristalizados pelos criadores de gado e pelo serviço militar. Esse grupo social, diante de tal condição, sofreu transformações e contribuiu com o processo de miscigenação racial, o que ocasionou o rápido povoamento do Estado. Nesse período, em meados do século XIX, os habitantes da Província do Rio Grande do Sul eram divididos entre os denominados "continentinos" ou "rio-grandenses" e os "gaúchos", índios, negros, numa forma de exclusão desses grupos marginalizados.

A partir das situações de guerras e revoluções, mais precisamente, a Revolução Farroupilha e a Guerra do Paraguai, ainda no século XIX, ocorre uma (re)significação da designação "gaúcho". A Revolução Farroupilha, pode ser considerada um exemplo da representação do gaúcho como livre e insubordinado, características antes daqueles 
considerados marginais, advindos da região do pampa uruguaio e argentino conforme já mencionado. Mas somente no início do século XX, essa (re)significação do imaginário sobre o "gaúcho" e consequentemente, esta designação, tornou-se representativa de parte dos habitantes do RS, pois aqueles que viviam no campo ainda eram vistos com maus olhos, ou seja, ainda emergiam do interdiscurso sentidos taxativos à designação gaúcho, àqueles sujeitos do campo. Nas palavras de Petri (2004), "são os sentidos pejorativos constitutivos da memória que impedem a identificação plena do homem do campo com a designação gaúcho" (p. 130).

Todavia, foi esse contexto revolucionário, tal como aponta a autora citada, que contribuiu com o processo de (re)significação da designação "gaúcho", atribuindo-lhe novos efeitos de sentido e apagando aqueles sentidos pejorativos, num movimento entre o lembrar e o esquecer próprio da memória discursiva. Nesse sentido, este período sócio-histórico, é marcado pela (re)construção do imaginário social de um povo que é resultado das disputas territoriais e das miscigenações. O rompimento com o velho, assim, produziu um efeito de evidência ao novo sentido, um sentido relacionado ao heroísmo, nos levando a acreditar (ilusoriamente) que a designação "gaúcho" está liberta de sua conotação taxativa.

Este novo efeito de sentido para a designação "gaúcho", é reforçado pelo discurso literário e pelos aparelhos estatais, como a escola e os museus, que idealiza o gaúcho como figura heroica. Não se trata mais de um sujeito à margem, conforme salienta Petri (2004), mas de um sujeito representativo com o qual todo grupo social se identifica. Enfim, a designação "gaúcho" ganha outro funcionamento no interior da FD, bem como o discurso produzido sobre ele.

A partir do século XX, considera-se gaúcho todos os habitantes do RS, no meio rural ou no meio urbano, consolidando uma formação imaginária que os destaca das demais regiões do país, por suas características formidáveis, tais como: coragem, labuta, honestidade, honra, patriotismo, companheirismo, hospitalidade etc.

É nesse contexto sócio-histórico que situamos a nossa pesquisa e que trazemos a tatuagem em pauta, na medida em que enfatizamos a questão da constituição do sentido, seguindo o legado pecheuxtiano - o sentido não existe em si numa relação de transparência com o significante. Pêcheux (1988/2009) escreve que, "o sentido [...] não existe em 'si mesmo' [...], mas, ao contrário, é determinado pelas posições ideológicas que estão em jogo no processo sócio-histórico no qual as palavras, expressões e 
proposições são produzidas (isto é, reproduzidas)" (p. 146). Nessa perspectiva, as palavras ou, pensando no nosso objeto de estudo, a tatuagem, adquire sentido em referência à FD em que o sujeito está inscrito, e os sentidos podem mudar segundo a posição sustentada pelo sujeito que os empregam.

Em relação à tatuagem da bandeira do $\mathrm{RS}$, os sentidos são atribuídos em consonância aos saberes que estão no interior da FD, na qual o sujeito que se tatuou está inscrito, em outras palavras, o sujeito é interpelado a atribuir sentido à tatuagem pela FD que, na linguagem, representa a FI que lhe subjaz. O sentido, assim, é constituído em cada FD, nas relações que tais palavras ou tattoos mantêm com outras palavrastattoos da mesma FD ou de outra. Por isso, pensamos no sentido como resultado de um processo discursivo, em que podem ou não ser atualizados na rede de formulações possíveis, de acordo com a condição de produção e a posição-sujeito em que o sujeito tatuado se inscreve. Cabe, agora, apresentarmos a tatuagem a que tanto no referimos:

Sequência discursiva $(\mathrm{SD})^{8}$ :

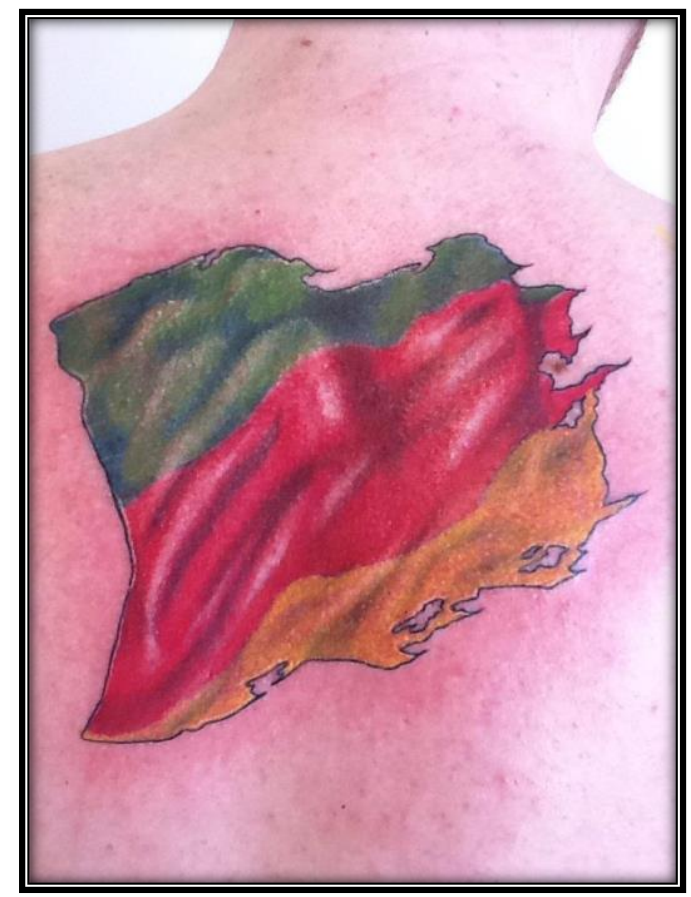

Figura 1 - Fotografia da tatuagem da bandeira do RS do sujeito tatuado ${ }^{9}$. Foto tirada em: 04/06/2015

\footnotetext{
8 Trabalhamos a noção de sequência discursiva (SD) como denominou Courtine (1981/2009) em sua tese. Segundo o autor, a SD, metodologicamente, é representativa de uma série de outras sequências que possuem similaridade no funcionamento discursivo em análise.

${ }^{9}$ Essa fotografia foi retirada do site de rede social "Facebook", na data de 4 de junho de 2015. O link completo não será disponibilizado para não comprometer o usuário da conta. Além do mais, na $\mathrm{AD}$ não nos preocupamos com o sujeito empírico, mas com sua posição-sujeito.
} 
Esta tatuagem foi publicada na rede social Facebook no dia 22 de setembro do ano de 2012, pelo tatuador em sua página particular, marcando o nome do sujeito tatuado e o local de trabalho, utilizando a legenda "Semana Farroupilha. Ótimo find!". Ou seja, na semana em que se comemoram os ideais farroupilhas, o sujeito tatuou em seu corpo discursos relacionados ao seu sentimento pelo Estado, (re)produzindo sentidos. Estes sentidos podem ser relacionados a tantos outros discursos que circulam socialmente próprios ao tradicionalismo, como aqueles presentes em músicas, programas de rádio e televisivos, literatura. Dentre todos, podemos citar a composição de Elton Saldanha, "Eu sou do sul, é só olhar para ver que eu sou do sul" ${ }^{10}$, que pode ser pensada como uma paráfrase da tatuagem em pauta.

A imagem, pelas curtidas e comentários, foi bem aceita pelos amigos do tatuador e do sujeito tatuado, usuários permitidos à visualização do conteúdo pelo proprietário da conta que postou em modo "amigos". Assim sendo, a circulação da foto torna-se limitada e, provavelmente, tenha sido lido/vista pelo círculo de amigos desses dois sujeitos. Tais informações sobre as condições de produção específicas do objeto analisado podem responder às perguntas enunciativas que se fazem importantes na leitura. Todavia, nosso interesse está em compreender o imaginário que perpassa o gesto do sujeito em tatuar tal imagem e, as possíveis leituras que podem ser feitas pela visualização da tattoo além da internet.

Em nosso ponto de vista, esta SD pode nos ajudar a compreender a relação não objetiva do sujeito com seu corpo na medida em que os sujeitos, assim como os sentidos, na perspectiva a qual nos filiamos, constituem-se concomitantemente por processos em que interferem a ideologia, o inconsciente, a memória e o imaginário. Nesse viés, acreditamos que a análise se faz importante, pois é através dela que podemos compreender o imaginário sobre o gaúcho e sua pátria que condiciona o sujeito e o incita a produzir sentidos, no caso, por meio do gesto de se tatuar, construindo/reproduzindo em seu corpo discursos textualizados na tatuagem da bandeira do RS.

Conforme já salientado, este sujeito é afetado por um imaginário social acerca dos valores de seu Estado, consequentemente, o discurso se (re)produz a partir desse imaginário. Segundo os pressupostos teóricos da $\mathrm{AD}$, “o imaginário faz necessariamente parte do funcionamento da linguagem. Ele é eficaz. Ele não brota do

\footnotetext{
${ }^{10}$ Fonte: Disponível em: <https://www.letras.mus.br/elton-saldanha/159131/ >. Acesso em 11/04/17.
} 
nada: assenta-se no modo como as relações sociais se inscrevem na história e são regidas, em uma sociedade como a nossa, por relações de poder" (ORLANDI, 2012c, p. 42).

Com base nos estudos de Petri (2004), entendemos que, na contemporaneidade, o imaginário que perpassa a FD que ela denomina de Formação Discursiva Gaúcha, é de um gaúcho-herói, ou seja, os sentidos constituídos nessa FD, nas condições de produção atuais, são relacionados às qualidades positivas desse sujeito gaúcho. Utilizando-nos das palavras da autora, efetiva-se "uma formação imaginária que destaca esse grupo social e regional por suas características mais elogiáveis" (PETRI, 2004, p. 134). Salientamos que essa denominação dada pela autora trata dos sujeitos habitantes do Rio Grande do Sul, enfatizando a construção/instituição da imagem do gaúcho ao longo dos tempos. Neste trabalho, fazemos referência a essa FD tratando-se dos pressupostos ideológicos e à imagem do gaúcho tal como propõe a autora, porém ressaltamos que não generalizamos a delimitação da FD para todos os sujeitos habitantes do RS, mas para a parte que se identifica com os pressupostos ufanistas que circulam nessa FD, portanto acreditamos pertinente nomeá-la como "Preito-gaúcha".

O sujeito tatuado, então, inscrito nessa FD, no momento da Semana Farroupilha $^{11}$, textualiza sentidos na sua pele, como uma forma de identificação aos pressupostos dessa FD. Trazendo as considerações de Ferreira (2012), a tatuagem é marca de identidade que reflete as características biográficas do sujeito, dito de outra maneira, ancoradas na $\mathrm{AD}$, a tatuagem manifesta uma posição-sujeito que significa em relação ao contexto sócio-histórico e a FD, ou seja, é uma tomada de posição do sujeito tatuado que se identifica com os saberes da FD que valorizam o gaúcho.

Congruente a isso, o sujeito faz uso da tatuagem como forma de dar mais visibilidade ao seu corpo, mais poder tal como propõe Orlandi (2004), ou também como forma de individualizar-se do social (ORLANDI, 2012a). Nesse aspecto, acreditamos que o funcionamento de individualização pode se dar de duas maneiras, de um lado, o sujeito se tatua para individualizar seu corpo, desejando visibilidade, de outro lado, o sujeito se tatua com a bandeira do RS para se individualizar, juntamente com outros

\footnotetext{
${ }^{11}$ A Semana Farroupilha é uma festividade promovida durante o mês de Setembro, em referência ao dia 20 de setembro, dia que os farroupilhas, liderados por Bento Gonçalves, venciam o confronto da Ponte da Azenha e entravam na Província de Porto Alegre. Iniciou-se, dessa forma, a mais longa guerra do território brasileiro, a Revolução Farroupilha, que resultou na declaração de independência do Estado, com novos pressupostos sociais e políticos.
} 
sujeitos gaúchos, do país, numa forma de idolatria ao Estado, como Estado singular, único, como se fosse superior aos demais estados brasileiros.

Nesse caminho, acrescentamos o que escreve Pires (2001) sobre a tatuagem, considerando-a um registro onde os sentidos são perpassados por uma historicidade. Sendo assim, ao textualizar a bandeira do RS, mais precisamente, a bandeira farrapa, na Semana Farroupilha, o sujeito salienta sentidos relacionados aos ideais revolucionários, produzindo efeitos de sentido, recuperados pelo viés da memória discursiva, relacionados ao gaúcho rebelde. Este sentido é (re)significado pelo sujeito tatuado na medida de que rebeldia não se aproxima a sentidos pejorativos, como nos séculos XVII e XVIII, mas reafirma a ideia de insubordinação à Federação, colocando seu Estado como pátria, como nos séculos XIX e XX, marcados por guerras e revolução.

O sentido atribuído pelo sujeito tatuado a sua tattoo, conforme a leitura que fazemos, realça o discurso ufanista dos gaúchos, silenciando outros que já significaram. Orlandi (2012c) nos lembra que, "as relações de poder em uma sociedade como a nossa produzem sempre a censura, de tal modo que há sempre silêncio acompanhando as palavras" (p. 83). Nesse viés, cabe-nos pensar o que foi dito sobre a origem do gaúcho e o que não pode ser dito na FD em que o sujeito tatuado está inscrito, no contexto histórico-social da contemporaneidade, mais ainda, a Semana Farroupilha. Talvez, possamos relacionar esse silenciamento do gaúcho enquanto bandido e malfeitor, ao fato de que os sentidos que perpassam a FD "preito-gaúcha" são sentidos positivos e, não negativos/pejorativos, pois considerar esses sentidos pejorativos colocaria em pauta o imaginário sobre o gaúcho bom e patriota, construído ao longo dos tempos.

Cazarin (2005), parafraseando Sercovich (1997), escreve que, “o imaginário discursivo não se explica através de uma determinada realidade, e sim como se derivando de determinados interesses sociais" (p. 140). Se bem entendemos essa citação, podemos escrever que os interesses que constituem a FI que subjaz à FD em que se inscreve o sujeito tatuado, incitam a cristalização de saberes ufanistas, uma vez que considerar sentidos antagônicos seria desfazer a evidência histórica. Nesse processo discursivo de atribuição de sentidos, observamos, assim, a presença do político, enquanto relações de força, em especial quando o sujeito tatuado produz um discurso de grandeza de seu Estado, atestando o orgulho de ser gaúcho.

Diante do exposto, salientamos o fato de que o sentido da tatuagem não existe “em si mesmo", pois é determinado pelas posições ideológicas presentes no processo 
em que é produzido. Nessa perspectiva, entendemos que o sentido da tatuagem da bandeira do RS não está unicamente no seu desenho, mas aquém e além dele, pois na sua construção/formulação/textualização interferem o imaginário, a memória, o inconsciente e a ideologia.

\section{Considerações finais}

Como um efeito de fechamento do texto, esclarecemos que a leitura que fazemos é uma possibilidade dentre outras que podem ser produzidas, dependendo dos efeitos de memória que nelas sejam mobilizados. Lembramos e retomamos, em cada estudo, que as tatuagens são gestos simbólicos materializados no corpo de sujeitos que podem produzir múltiplos sentidos. Essa constatação torna-se possível, na medida em que entendemos a questão da constituição do sentido, seguindo o legado pecheuxtiano.

Não acreditamos na transparência da linguagem e, por conseguinte, em uma interpretação objetiva, porque os sentidos podem ser sempre outros, o que não significa que eles possam ser quaisquer um e que todas as interpretações sejam pertinentes. Esta afirmação vale tanto para o sujeito que se tatuou - quando da formulação do sentido da sua tattoo -, quanto para os leitores de sua tatuagem, ou para nós analistas, pois os sentidos não estão presos ao desenho. Por isso, enfatizamos que a leitura empreendida aqui é uma possibilidade, e que mesmo reconhecendo a indicação de que o analista precisa ser o menos subjetivo possível, a nossa leitura também parte de uma posiçãosujeito.

Nesse viés, retomando nosso objeto de análise e o sujeito tatuado, lembramos que os sentidos foram construídos historicamente por um sujeito inserido numa FD específica, a que nomeamos de preito-gaúcha, ocupando um determinado lugar social, em que tais sentidos são necessários à manutenção da ordem estabelecida socialmente, aquela que legitima os pressupostos ufanistas em relação ao Estado do Rio Grande do Sul, estabelecendo relações desiguais de poder das demais regiões brasileiras.

Como ressalta o Hino do Estado em questão: "Mostremos valor constância. Nesta ímpia e injusta guerra. Sirvam nossas façanhas. De modelo a toda Terra”. Dito diferentemente: sirvam nossas façanhas, nossos valores, nossos costumes, como exemplo de um povo que ilusoriamente acredita ser superior..., imaginário esse reforçado pelas instâncias ideológicas que nos instigam a refletir a quem esse discurso favorece, quais são os interesses em jogo? Questões para trabalhos futuros. E que as inquietações não cessem! 


\section{Referências}

CAZARIN, E. Identificação e representação política: uma análise do discurso de Lula. Ijuí: Unijuí, 2005.

ERNST-PEREIRA, A. Corpo e Subjetividade: "efeitos" dos cosméticos. In: Seminário Internacional Fazendo Gênero. n. 6, 10 a 13 de ago., 2004. Santa Catarina. Anais do evento, 2004. p. 1-7.

FERREIRA, D. O corpo como texto: análise discursiva da escrita no corpo. Eventos pedagógicos. n. 1, v. 3, abr., 2012. p. 138-146.

LEANDRO-FERREIRA, M. O corpo enquanto objeto discursivo. In: PETRI, V.; DIAS, C. (orgs.). Análise do Discurso em perspectiva: teoria, método e análise. Santa Maria: Editora da UFSM, 2013. p. 99-107.

ORLANDI, E. Textualização do Corpo: A escritura de si. In: Cidade dos Sentidos. Campinas, SP: Pontes, 2004. p. 119-128.

. À flor da pele: indivíduo e sociedade. In: Discurso em Análise: Sujeito, Sentido e Ideologia. 2. ed. Campinas, SP: Pontes Editores, 2012a. p. 187-197.

Processos de significação, corpo e sujeito. In: Discurso em Análise: Sujeito, Sentido e Ideologia. 2. ed. Campinas, SP: Pontes Editores, 2012b. p. 83-96.

Sujeito, história, linguagem. In: Análise de Discurso: princípios e procedimentos. 10. ed. Campinas, SP: Pontes Editores, 2012c. p. 22-55.

PÊCHEUX, M. Semântica e Discurso (1975). ORLANDI, E. et al. (Trad.). Campinas, SP: Editora da UNICAMP, 1988/ 2009.

Análise Automática do Discurso (AAD - 69). In: GADET, F; HAK, T. (Orgs.).

Por uma análise automática do discurso. 4. ed. MARIANI, B. et al. (Trad.). Campinas, SP: Editora da Unicamp, 1990/2010.

PETRI, V. Imaginário sobre o gaúcho no discurso literário: da representação do mito em 'Contos Gauchescos', de João Simões Lopes Neto, à desmitificação em 'Porteira Fechada', De Cyro Martins. 2004. 332 f. Tese de Doutorado. Universidade Federal do Rio Grande do Sul - UFRGS. Porto Alegre, mai., 2004.

PIRES, B. Piercing, implante, escarificação, tatuagem. O corpo como suporte da arte. 2001. 229 f. Dissertação de Mestrado. Universidade Estadual de Campinas UNICAMP. Campinas, nov., 2001.

SILVA, N. Tatuagens: sujeitos e sentidos. 2014. 153f. Dissertação de Mestrado. Universidade Católica de Pelotas - UCPEL. Pelotas, dez., 2014. 


\section{Para citar essa obra:}

SILVA, N. S., LIMA, S. A. L.. O discurso ufanista materializado no corpo. In: RUA [online]. $\mathrm{n}^{\circ}$. 23. Volume 1, p. 49 - 61 - e-ISSN 2179-9911 - JUNHO/2017. Consultada no Portal Labeurb - Revista do Laboratório de Estudos Urbanos do Núcleo de Desenvolvimento da Criatividade.

http://www.labeurb.unicamp.br/rua/

Capa: Figura 1 -Fotografia da tatuagem da bandeira do RS do sujeito tatuado. Foto tirada em: 04/06/2015

\section{Laboratório de Estudos Urbanos - LABEURB}

Núcleo de Desenvolvimento da Criatividade - NUDECRI

Universidade Estadual de Campinas - UNICAMP

http://www.labeurb.unicamp.br/

\section{Endereço:}

LABEURB - LABORATÓRIO DE ESTUDOS URBANOS

UNICAMP/COCEN / NUDECRI

CAIXA POSTAL 6166

Campinas/SP - Brasil

CEP 13083-892

Fone/ Fax: (19) 3521-7900

Contato: http://www.labeurb.unicamp.br/contato 